DOI 10.37882/2223-2974.2020.12.29

\title{
ГОСТИНИЧНЫЙ БИЗНЕС И УПРАВЛЕНИЕ ДОХОДАМИ ОТЕЛЯ В ПЕРИОД КРИЗИСА, ВЫЗВАННОГО ПАНДЕМИЕЙ КОРОНАВИРУСА
}

\section{HOTEL BUSINESS AND INCOME MANAGEMENT DURING THE COVID PANDEMIC CRYSIS}

\section{O. Romashkina \\ G. Krasnozhenova}

Summary: Current state of hotel business and profitable hotel anticrisis management is a subject of current research. COVID pandemic's influence on touristic influence and hotel industry income is being analyzed. International touristic flows as a hospitality enterprise income factor is provided. Anti-crisis methods of hotel's income management including pandemic period pricing strategy choice is being examined. Practical recommendations for hotel enterprises on dynamic tariffs use, scientifically based room management, sales \& marketing, operational process change and multiple income sources optimization are provided. Research methodology: international statistics, scientific sources and hotel industry practice analysis to create value proposition for independent hotel enterprises during COVID pandemic. Actual ways and modern strategies for hotel income increase strategy are provided in this research. Outcomes on hotel's higher crisis resistance, significant capitalization increase during pandemic followed by its competitiveness grow in a highly aggressive environment are bein provided.

Keywords: hotel business, income management, hotel enterprise, crisis, COVID-19 pandemic, anti-crisis management, pricing policy, pricing strategies, dynamic tariffs, customer service innovations.

\author{
Ромашкина Ольга Петровна \\ дочент, Московский государственный \\ лингвистический университет \\ romash98@mail.ru \\ Красноженова Галина Федоровна \\ Д.с.н., профессор, Московский государственный \\ лингвистический университет
}

Аннотация: Предметом исследования является состояние гостиничного бизнеса в период пандемии COVID-19 и антикризисное управление доходностью отеля. Анализируется влияние пандемии коронавируса на индустрию туризма и доходы гостиничного бизнеса. Приводится статистика международных туристских потоков как фактора доходности предприятий гостеприимства. Рассматриваются антикризисные методы управления доходами отеля, включая выбор стратегии ценообразования на период пандемии. Даются практические рекомендации гостиничным предприятиям по применению динамических тарифов, научно-обоснованному управлению номерным фондом, маркетингом и продажами, изменению операционныхпроцессов гостиницы, оптимизации нескольких центров доходности. Метод исследования: анализ международной статистики, научных источников и практики гостиничной индустрии с целью синтеза предложений по выбору антикризисной политики для независимых гостиничных предприятий в период борьбы с пандемией коронавируса. В работе предлагаются актуальные пути и современные стратегии увеличения доходности отеля. Делаются выводы 0 высокой кризисной устойчивости гостиничного бизнеса, о возможности существенного повышения капитализации гостиничного предприятия в условиях пандемии и, как следствие, усиления его конкурентоспособности и выживаемости в условиях высоко агрессивной окружающей среды.

Ключевые слова: гостиничный бизнес, управление доходами, гостиничное предприятие, кризис, пандемия COVID-19, антикризисное управление, ценовая политика, стратегии ценообразования, динамические тарифы, инновации в обслуживании.
$\mathrm{P}$ аспространение пандемии коронавируса существенно изменило жизнь всей планеты и каждого человека на ней. Ее пагубное влияние на мировую экономику [1, 2, 3,4], и международную торговлю [5], распространяется на все отрасли, но среди наиболее пострадавших - туризм, пассажирский авиационный транспорт и гостиничный бизнес, напрямую зависящий от интенсивности туристских потоков.

В большинстве стран мира происходит переориентация экономики [6], в том числе туристского [7] и гостиничного бизнеса. Прогнозируются существенные изменения маркетинговых взаимоотношений в сфере международного туризма [8].
Гостиничный рынок несет огромные потери, не все отели смогут дождаться ситуации, когда начнет расти их RevPAR (выручка на доступный номер). Конечно, любой кризис в той или иной степени является причиной санации рынка: первыми выходят из игры наименее профессиональные игроки. Однако на наиболее уязвимых рынках пострадают и добросовестные предприятия.

При этом восстановление гостиничной индустрии может занять до нескольких лет. Меры по обеспечению безопасной дистанции, вводимые перевозчиками, надолго повлекут за собой снижение туристических потоков и неудобства для путешественников и после открытия границ. 
Единственная возможность для отеля выжить в реалиях огромных убытков - разработка серьезной адаптивной антикризисной программы действий по управлению своими доходами.

Более полувека туризм являлся одной из самых динамично развивающихся отраслей мировой экономики и показывал высокие темпы роста. Даже в шоковых условиях экономических кризисов, политической и военной нестабильности некоторых регионов, угрозы международного терроризма в мировой индустрии туризма сохранялась непрерывная положительная тенденция к росту (см. рис.1). Среднегодовой прирост международных туристских прибытий за рассматриваемые годы составил около $4 \%$ [9].

Статистика темпов роста туристских прибытий дает наглядную иллюстрацию вызванных самыми разными проблемами многочисленных кризисов, переживаемых индустрией гостеприимства (см. рис 2).

Рассмотрим несколько примеров. Вспышка свиного гриппа в 2009 г., замедлившая темпы роста практически на 5\%, тоже распространялась высокими темпами, однако не повлекла полного ограничения перемещений и закрытия границ.

После теракта 11 сентября 2001 г. в Вашингтоне и Нью-Йорке (снижение темпов роста прибытий почти на 3\%) на несколько дней было закрыто воздушное пространство США. Последствия казались тогда глобальными: усилился страх перед авиаперелетами, ужесточились правила безопасности и досмотров при воздушных перевозках.

В 2010 г. в Исландии облако пепла, образовавшееся

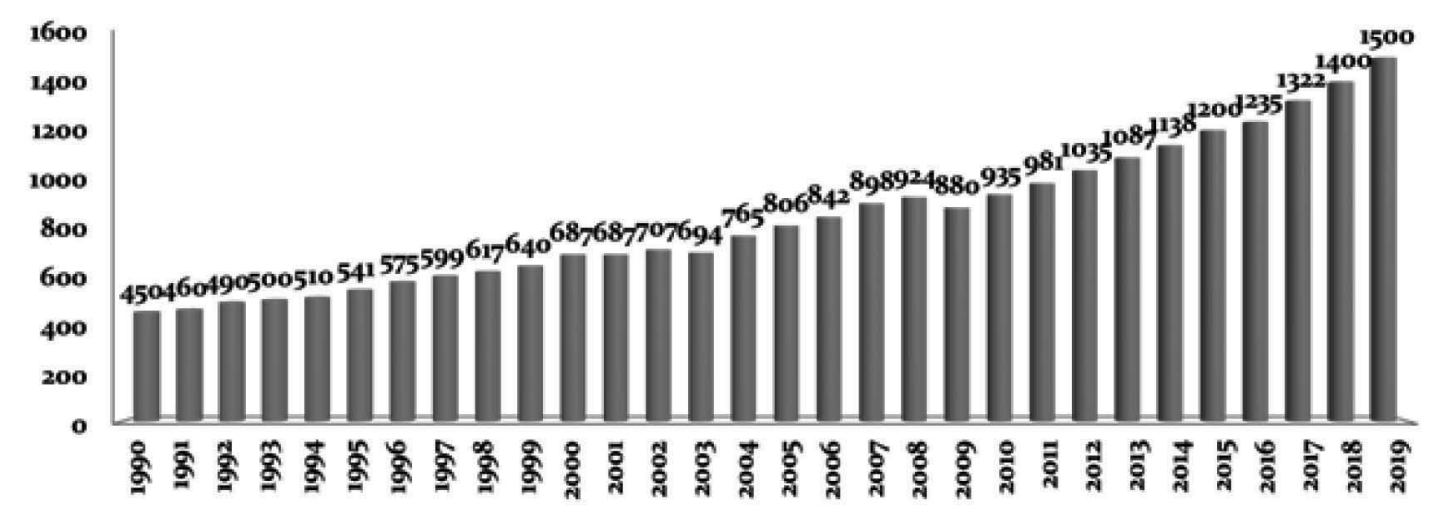

Рис. 1. Въездной туризм: международные туристские прибытия 1990-2019 гг. (млн.)

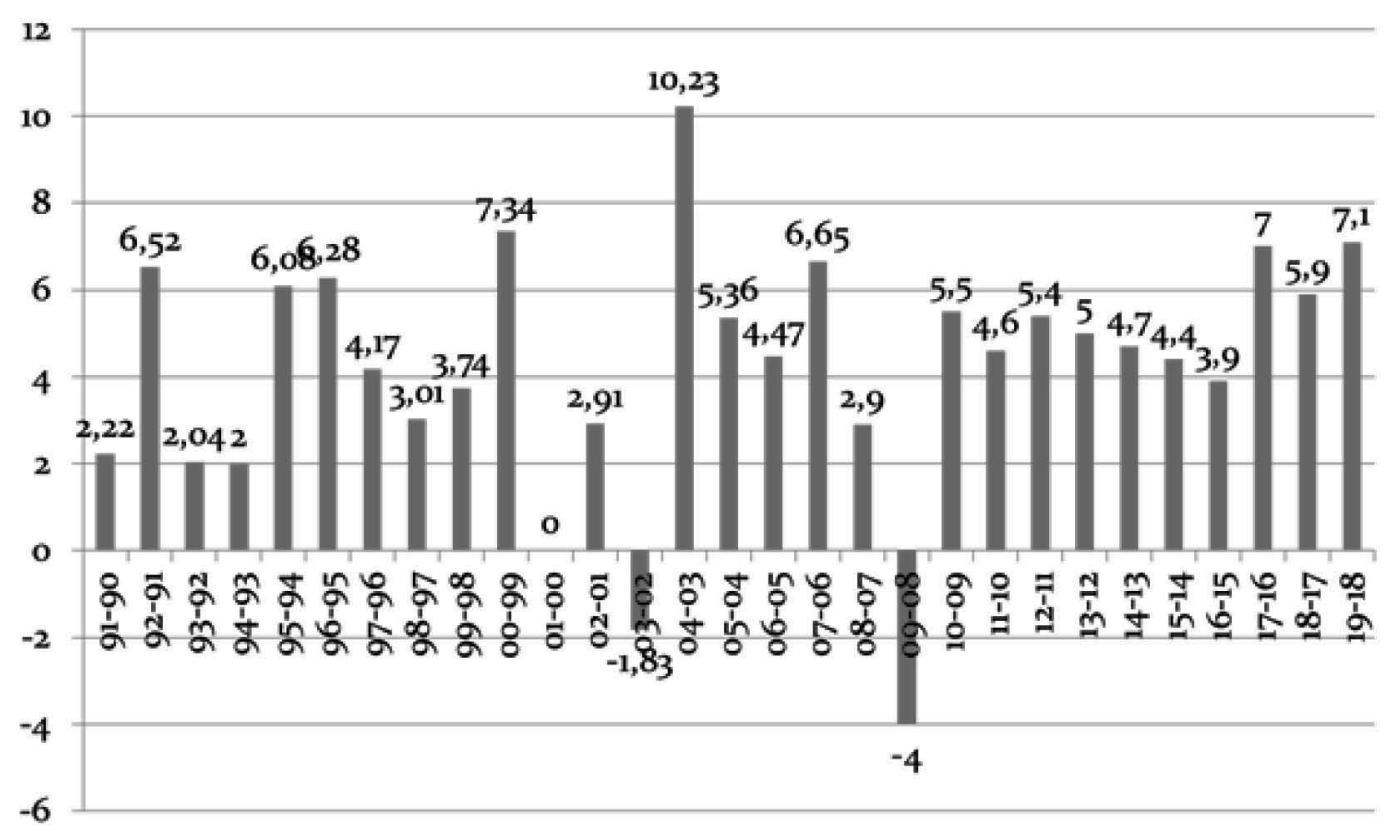

Рис. 2. Темпы роста туристских прибытий 1990-2019 гг., \% 
при извержении вулкана Эйяфьядлайекюдль, мешало функционированию двигателей самолетов, что привело к закрытию воздушного пространства над Европой. Однако этот кризис серьезных последствий не имел и статистика быстро восстановилась.

По оценке Всемирного совета по туризму и путешествиям (World Travel \& Tourism Council) из-за вируса SARS в 2003г. работу в сфере туризма в Китае, Гонконге, Вьетнаме и Сингапуре потеряли около 3 млн. человек. Так, в частности, руководство аэропорта Гонконга сообщало о снижении пассажирского трафика на 68,9% [10].

Глобальный финансовый кризис 2008-2009 гг., привел к сокращению производства и доходов населения, и это существенно сказалось на количестве поездок туристов (спад на 3,5\% в 2009 году по сравнению с 2008). Однако риск экономического спада, иные политические и гуманитарные риски всё в меньшей степени сказываются на росте туризма, так как спрос на услуги данной сферы имеет свои собственные детерминанты [11].

Индустрия гостеприимства всегда проявляла высочайшую устойчивость к многочисленным глобальным и региональным кризисам и показывала самые высокие темпы восстановления. В частности, рост показателя доходности гостиничного предприятия RevPAR происходит обычно довольно быстро.

Однако даже на фоне множества минувших кризисов нынешний, вызванный COVID-19, выглядит наиболее зловещим. Это связано и с гораздо большей длительностью, и с беспрецедентными мерами борьбы, и с более высокой степенью неопределенности.

По данным Всемирной туристской организации (UNWTO) при ООН количество международных туристских прибытий в 2020 году сократилось на 70\%. Число туристов в мире в период с января по август 2020 года на 700 миллионов меньше, чем за тот же период годом ранее. Это уже привело к потере доходов в размере 730 миллиардов долларов - более чем в восемь раз больше, чем было зарегистрировано после экономического кризиса 2009 г. [12].

Убытки и проблемы для разных игроков рынка тоже неодинаковы. Различные регионы, страны, типы отелей испытывают разное по разрушительности влияние кризиса. Можно выделить критерии, которые существенно увеличивают степень уязвимости гостиницы:

- необходимость закрытия по указу властей или изза полного отсутствия постояльцев;

- предоставление отелем полного комплекса услуг;

- расположение в больших городах с большим потоком международных посетителей;

- зависимость от наличия чартерных рейсов;
- аренда здания у собственников с фиксированной арендной платой.

В то же время относительно спокойно чувствуют себя курортные или загородные отели.

В России, сделавшей ставку на внутренний туризм, ситуация существенно лучше, чем по миру в целом. Туристский поток в прошедшем летнем сезоне сократился всего на 10\% по сравнению с летом 2019 года. Такой показатель можно считать неплохим: в 2020 году сезон полноценно стартовал только с начала июля.

При этом ситуация в разных регионах РФ сложилась различная. В Крыму летом 2020 года отдохнуло в 1,5 раза больше туристов. Краснодарский край прибавил 15\% к предыдущему лету, Такого спроса на гостиницы Черноморского побережья не было даже в 2016 году, когда была закрыта ,

В этих условиях невозможно переоценить важность грамотного ценообразования в гостиничном бизнесе. Бесконтрольное снижение цен будет иметь долгосрочные последствия и препятствовать восстановлению экономики. Прежде всего, отели должны повысить ценность предложения, не увлекаться скидками, продумать будущую сегментацию.

В сложившейся ситуации на первый план выходит ценообразование в зависимости от уровня тарифов конкурентов. В этой категории выделяют пять стратегий.

- Стратегия «снятия сливок» - принцип увеличения ценности предложения. Делаем цену выше конкурентов, но добавляем услугу, например, сауну, парковку или ранний заезд. Эта стратегия будет хорошо работать в том случае, если у отеля высокий рейтинг и отличные отзывы. В идеале, в глазах гостей отель должен превосходить по какому-то параметру конкурентов, будь то расположение, уровень сервиса или оценки на сайтах.

- Стратегия «соответствия». При данной стратегии отель выставляет цену, равную цене конкурента, на минимальный тариф с ограничениями, а стандартный тариф с гибкими условиями отмены ставится дороже. Если отель уже понравился, и цена показалась привлекательной, гость может согласиться на более строгие условия отмены.

- Стратегия «Окружение и победа!». В данном случае отель выставляет минимальную цену с ограничениями уже ниже, чем стандартная цена у конкурента, а тариф без ограничений должен быть чуть выше. Этот метод отлично зарекомендовал себя в условиях тяжелой конкурентной борьбы. В онлайн системах бронирования в условиях кризиса гости часто реагируют на цену и идут туда, где дешевле. Гость зайдет на станицу отеля, и по- 
является шанс соблазнить его на дополнительные затраты предложением более высокой категории номера или повышенной с помощью дополнительной услуги ценностью стандартного тарифа.

- Стратегия «подсечки». Эта стратегия предполагает, что предлагается стандартный тариф, равный тарифу конкурента, а минимальный тариф с ограничениями немного ниже. Этот метод уже несет в себе некоторые риски демпинга, так как конкурент может ответить на этот ход зеркальным понижением тарифов.

- Стратегия «Выживания». Отель в данном случае ставит все тарифы ниже конкурента. Очень опасный метод, так как может положить начало ценовым войнам и демпингу.

Но какую бы стратегию отель выбрал, важно понимать, что лучше быть ведущим объектом на рынке и задавать уровень цен, чем идти за кем-то. А, чтобы стать флагманом в своем ценовом сегменте, важно работать над уровнем сервиса, визуальным контентом и обязательно уделять внимание отзывам гостей.

Кризис показал, что невозможно сохранить конкурентоспособность, не проявляя гибкость и применяя только фиксированные тарифы. Необходимо динамическое ценообразование, поскольку именно цена является одним из основных факторов выбора клиентом гостиничного предприятия. Однако речь не идет о простом снижении тарифов по сравнению с конкурентами, поскольку при демпфировании проигрывают все игроки. Индикатором правильно рассчитанной ссылки является увеличение числа бронирований, в противном случае она принесет больше вреда, чем пользы, в частности снижая доход от тех гостей, которые и без скидки купили бы обслуживание. Оптимальным вариантом является разработка согласованной гибридной сетки динамических и контрактных тарифов. Согласование очень важ- но, поскольку распространение сегмента онлайн бронирования показало, что туроператоры и корпоративные компании не потерпят, если динамические онлайн тарифы станут ниже контрактных, и уйдут в системы онлайн бронирования, а это серьезный проигрыш для отеля в борьбе за постоянного клиента.

В период пандемии абсолютно все отели в ситуации падения спроса и массовых аннуляций столкнулись с необходимостью сокращения рекламных и маркетинговых бюджетов. Однако возобновление операционной деятельности неизбежно влечет за собой возобновление рекламной и маркетинговой активности и выбор рыночных сегментов, на которые она должна быть направлена. Ясно, что многим брендам придется изменить позиционирование, искать новые стратеги продвижения, оптимизировать сегментацию для выхода из кризиса. Кризис даст возможность исследовать тот тип гостей, которых отель может и хочет привлечь. Изменение сегментации целевой аудитории отеля ведет к изменению стратегии компании.

Для этого необходимо понимать, как пойдет восстановление рынка. Приоритеты восстановления приведены на рисунке 3.

На базе оценки прогнозов восстановления рынков и собственных целей необходимо выстроить антикризисную маркетинговую стратегию и определить последовательность маркетинговых действий. Как считают ведущие специалисты рынка, необходимо начинать с продвижения собственного сайта и метапоисковиков, которые первыми отреагируют на восстановление рынка. Информация и фотографии на сайте должны убеждать гостя, что отель открыт, что применяются все меры безопасности и дистанцирования. Затем перейти к платному размещению на сайтах онлайн туристских агентств (ОТА) и только после этого к платной рекламе в соцсетях,

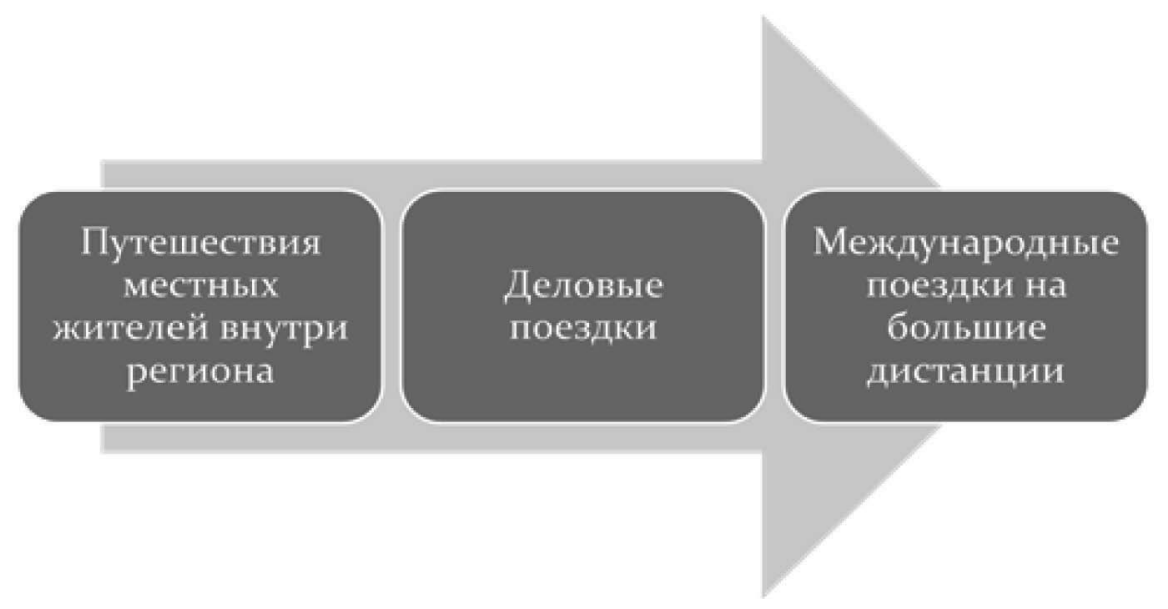

Рис. 3. Последовательность восстановления рынков туристских путешествий при выходе из кризиса, связанного с пандемией коронавируса 
к которой нужно относиться с осторожностью из-за риска негативных оценок в комментариях.

На этапе выхода из кризиса необходимо своевременно заняться проблемами ценообразования для увеличения дохода не только от номерного фонда, но и от других центров доходности отеля. Здесь нужно начинать с анализа показателей по каждому центру доходности. На предприятиях питания анализ показателя REVPASH (отношение общего дохода ресторана к количеству доступных мест и часов работы) покажет наиболее загруженные часы и периоды и те, которые требуют увеличения продаж. Эффективному распределению клиенто-потоков в СПА-салоне поможет анализ показателя загрузки REVPATH (средний доход на процедуро-час). Для анализа повременного спроса на конференц-зал или банкетный зал используется параметр REVPAM (отношение дохода от аренды к площади в квадратных метрах). Исходя из этих показателей, можно составить сводные таблицы и тепловые карты цен (периоды высокой, средней и низкой загрузки отмечаются разными цветами). Эти данные станут основой ценовой стратегии для дифференциации цен и применении «комплиментов» по дополнительным центрам доходности. Такая тактика поможет существенно увеличить капитализацию отеля в период выхода из кризиса.

В зависимости от ориентации отеля важным фактором повышения доходности может стать грамотное распределение номеров «дабл» (двухместная кровать) и «твин» (две раздельно стоящие кровати), при этом тариф на «твин» может быть более высоким. В то же время отелю с небольшим номерным фондом невыгодно вводить много категорий номеров, это неизбежно ведет к снижению загрузки.

Введение одновременно двух тарифных планов, с завтраком и без, может существенно повысить доходность, если уменьшение цены в тарифе будет меньше стоимости завтрака.

Освоение тактики активного использования апгрейдов (бесплатное повышение категории номера) и апсейлов (предложение номера высокой категории за небольшую доплату) - «высший пилотаж» управления номерным фондом - также приносит большие выводы. Особенно, если привязать вознаграждение сотрудников службы приема к количеству, проданных ими апсейлов непосредственно при поселении гостя.

Хороший эффект дает предварительное бронирование дополнительных услуг, персонифицированный сервис в номере.

В период кризиса наблюдается рост бронирований в последний момент, следовательно, имеет смысл предлагать специальные условия гостям, бронирующим обслуживание в последний момент.

Дополнительный доход от таких мер, не касающихся изменения ценовой политики, явно будет не лишним в кризисной ситуации.

Из вышесказанного можно сделать следующие выводы. Несмотря на беспрецедентность текущей ситуации с коронавирусом, гостиничный бизнес в целом обладает высокой степенью выживаемости и устойчивости к глобальным и региональным кризисам.

С целью повышения доходов в условиях высоко агрессивной окружающей среды отелям рекомендуются следующие действия:

- поиск способов сократить расходы и изменить операционные процессы;

- разработка специальных антикризисных программ оказания услуг и повышения их качества;

- соблюдение мер безопасности и адаптация бизнес-процессов;

- выбор антикризисной стратегии ценообразования;

- создание гибридной сетки согласованных динамических и контрактных тарифных планов;

- разработка маркетинговой стратегии и последовательности маркетинговых действий при восстановлении рынка, оптимизация сегментации;

- использование антикризисных принципов управления капитализацией для дополнительных центров доходности отеля.

При выполнении этих условий гостиничные предприятия имеют более высокие шансы для повышения своей капитализации в условиях пандемии и, как следствие, усиления конкурентоспособности и выживаемости.

\section{ЛИТЕРАТУРА}

1. Дзобелова В.Б., Гиголаева М.З., Дзеранова А.С., Туаева М.В., Керимова Л.Ч. Влияние коронавируса на экономику //Экономика и предпринимательство. 2020. № 3 (116). С. 1306-1308.

2. Морозов С.А. Каким будет ущерб от вспышки коронавируса для глобальной экономики? //Научный электронный журнал Меридиан. 2020. № 8 (42). C. 456-458. 
3. Овчаренко Я.Э., Козлова А.А., Молошникова А.Д. Влияние коронавируса на мировую экономику. //Междисциплинарный вектор развития современной науки: теория, методология, практика: Сборник статей II Международной научно-практической конференции. Петрозаводск, 2020. С. 25-29.

4. Павлова Д.А., Терентьева 0.Н. Влияние коронавируса на глобальную экономику. //Студенческий форум. 2020. № 13-1 (106). С. $73-74$.

5. Долгов С.И., Савинов Ю.А. Влияние вспышки нового коронавируса на международную торговлю. //Российский внешнеэкономический вестник. 2020. №2.C. 7-18.

6. Соломонова В.Н., Редькина Т.М. Стратегическая переориентация экономики под влиянием коронавируса. //Colloquium-journal. 2020 . № 10-8 (62). С. 38.

7. Антропова А.О. Влияние коронавируса (COVID-19) на международный туризм. //Вестник научных конференций. 2020. № 2-2 (54). С. 16-18.

8. Короткая А.М., Трофимова А.А. Влияние коронавируса на изменение маркетинговых инструментов в сфере международного туризма. //Инновационная экономика. 2020. № 1 (22). С. 28-38.

9. Ромашкина 0.П. Признаки устойчивого развития международного туризма как социально-экономической системы // Евразийское Научное 0бъединение. 2018. Т. 3. № 3 (37). С. 173-176.

10. Осипова, Л.Б. Гостиничный и туристический бизнес во время пандемии коронавируса COVID-19. // Молодой ученый. 2020 . № 23 (313). С. $429-433$.

11. Ромашкина 0.П. Туризм как фактор социально-экономической стабильности в период выхода из мирового экономического кризиса // Вестник Московского лингвистического университета. Выпуск: Экономика, Издательство МГЛУ, М., 2010 г.

12. UNWTO. Официальный сайт. URL: https://www.unwto.org/international-tourism-and-covid-19/ (дата обращения: 5.11.2020)

13. Итоги летнего сезона 2020. //Welcome Times. Журнал о гостиничном бизнесе. 2020. URL: https://welcometimes.ru/opinions/itogi-letnego-turisticheskogosezona-2020/ (дата обращения: 4.11.2020)

14. Трубилина М. Пали на поле брони. Сотни российских гостиниц не смогли пережить пандемию. //Российская газета. 2020. Столичный выпуск №239 (8293). URL: https://rg.ru/2020/10/21/sotni-rossijskih-gostinic-ne-smogli-perezhit-pandemiiu.html/ (дата обращения: 6.11.2020).

15. Kempinski. Официальный сайт URL: https://www.kempinski.com/ru/hotels/white-glove-service/ (дата обращения 29.10).

16. Four Seasons. Официальный сайт URL: https://press.fourseasons.com/news-releases/2020/lead-with-care-program/ (дата обращения 29.10).

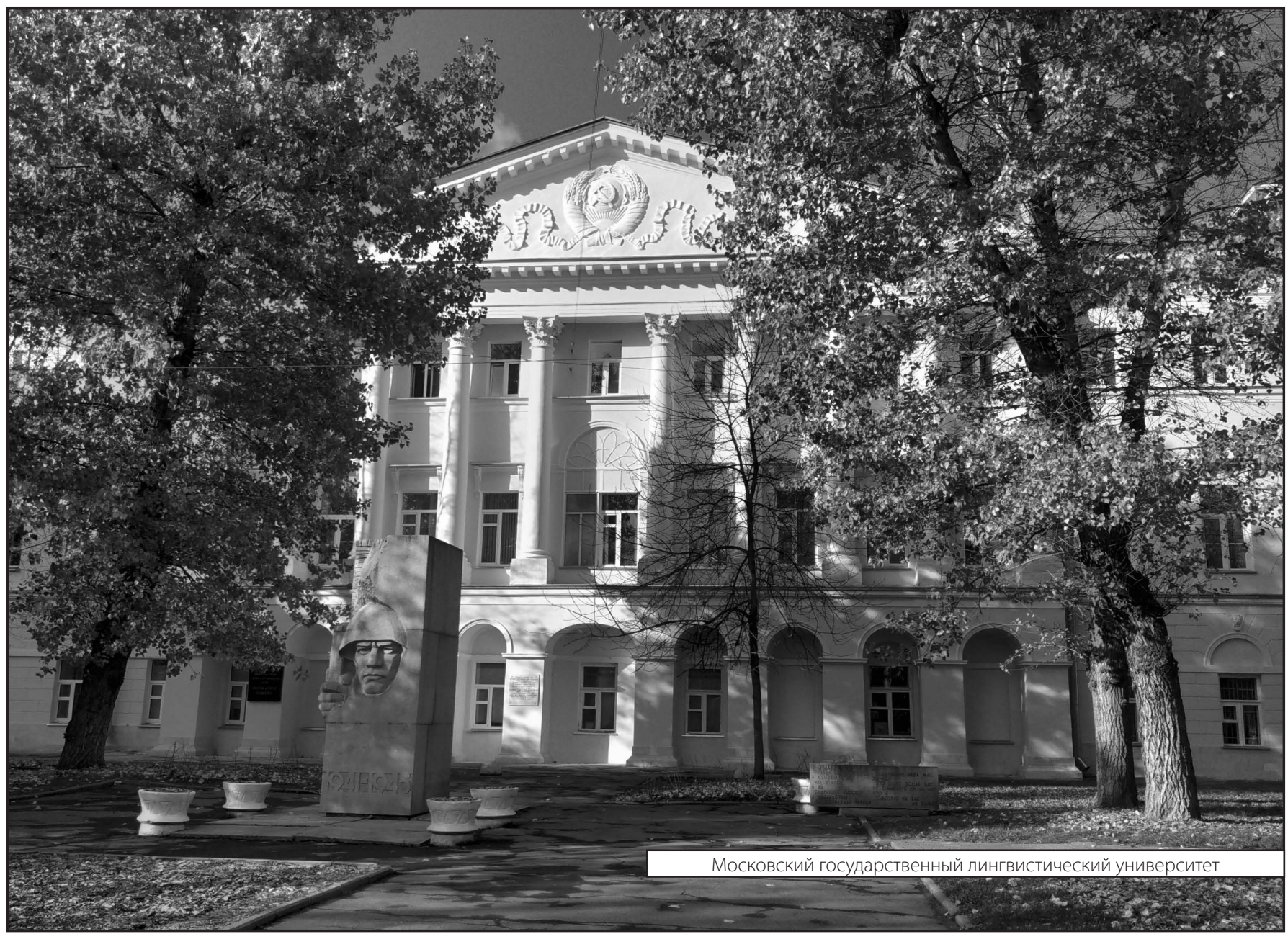

